\title{
Usefulness of Breast MRI for Safe Omission of Axillary Lymph Nodes Dissection in Sentinel Node-Positive Breast Cancer Patients
}

\author{
Hiromi Fuchikami, Naoko Takeda, Kazuhiko Sato \\ Department of Breast Oncology, Tokyo-West Tokushukai Hospital, Tokyo, Japan \\ Email: Hiromi.fuchikami@tokushukai.jp
}

How to cite this paper: Fuchikami, H., Takeda, N. and Sato, K. (2017) Usefulness of Breast MRI for Safe Omission of Axillary Lymph Nodes Dissection in Sentinel NodePositive Breast Cancer Patients. Journal of Cancer Therapy, 8, 1049-1057.

https://doi.org/10.4236/jct.2017.811089

Received: October 16, 2017

Accepted: November 25, 2017

Published: November 28, 2017

Copyright (c) 2017 by authors and Scientific Research Publishing Inc. This work is licensed under the Creative Commons Attribution International License (CC BY 4.0).

http://creativecommons.org/licenses/by/4.0/

\begin{abstract}
Background: Preoperative identification of patients with extensive lymph node metastasis (LNM) is important for safe omission of axillary lymph node dissection (ALND) in sentinel node (SN)-positive $(\mathrm{SN}+)$ breast cancer patients. Methods: We evaluated retrospectively the collected data of 758 breast cancer patients who underwent axillary surgery between 2008 and 2017, excluding those who received neoadjuvant chemotherapy. Results: Of the 758 patients, 607 were not suspicious to have LNM by axillary ultrasound (AUS-), but 38 suspicious cases were found by breast magnetic resonance imaging (MRI). Of 15 patients undergoing axillary fine needle biopsy (AFNA) due to second-look axillary ultrasound (AUS), 9 underwent ALND because of a positive AFNA (AFNA+). Among 81 (10.9\%) patients undergoing ALND due to SN+ findings, $6(7.4 \%)$ had extensive LNM (LNM $\geq 4$ ). If MRI was not performed, among the 90 of 673 patients undergoing ALND who had SN+ findings, 12 (13.3\%) had $\mathrm{LNM} \geq 4$. Conclusions: The proportion of cases with LNM $\geq 4$ was reduced from $13.3 \%$ to $7.4 \%$ among patients undergoing SN biopsies combined with breast MRI. ALND might be omitted safely in SN+ cases according to detailed preoperative evaluations using additional breast MRI to ultrasound.
\end{abstract}

\section{Keywords}

Breast Cancer, Sentinel Node, Axillary Lymph Node Dissection, Breast MRI

\section{Introduction}

Omission of axillary lymph nodes dissection (ALND) is standard for sentinel node $(\mathrm{SN})$-negative $(\mathrm{SN}-)$ breast cancer patients, but issues remain for SN-positive $(\mathrm{SN}+)$ patients. The American College of Surgeons (ACOSOG) trial Z0011 [1] 
and European Organization for Research and Treatment of Cancer (EORTC) 10981 [2] reported that ALND omission due to systemic therapy and radiation should be an option. The National Cancer Institute of Canada Clinical Trials Group MA.20 trial (NCIC-CTG MA20) [3] reported the significance of combining regional nodal irradiation (RNI) to ALND. Although lymph node metastasis (LNM) $\geq 4$ should be considered for RNI [3] [4], propriety is unknown regarding ALND omission.

At present, ALND is desirable in cases with extensive LNM, and SN biopsy requires appropriate preoperative evaluations. We assessed the possibility of predicting LNM $\geq 4$ for safe omission of ALND in SN+ patients.

\section{Patients and Methods}

We considered the usefulness of breast magnetic resonance imaging (MRI). We considered the accuracy of two types of examinations for axillary lymph node assessment: ultrasound only and ultrasound including a second-look axillary ultrasound (AUS) combined with MRI.

\subsection{Patients}

This retrospective study was done on 758 patients who underwent surgery between September 2008 and February 2017, excluding those who received neoadjuvant chemotherapy. Figure 1 shows a flow diagram of the examinations and surgery process at our hospital. ALND was performed in patients who had axillary fine needle aspiration biopsy (AFNA) class V (AFNA+) and SN+ findings. However, since January 2016, ALND has been omitted even for SN+ breast cancer cases to conserve surgery. We performed axillary irradiation in these cases.

\subsection{AUS Examination}

In our practice, we routinely perform an ultrasound (Aplio XG, Toshiba Medical

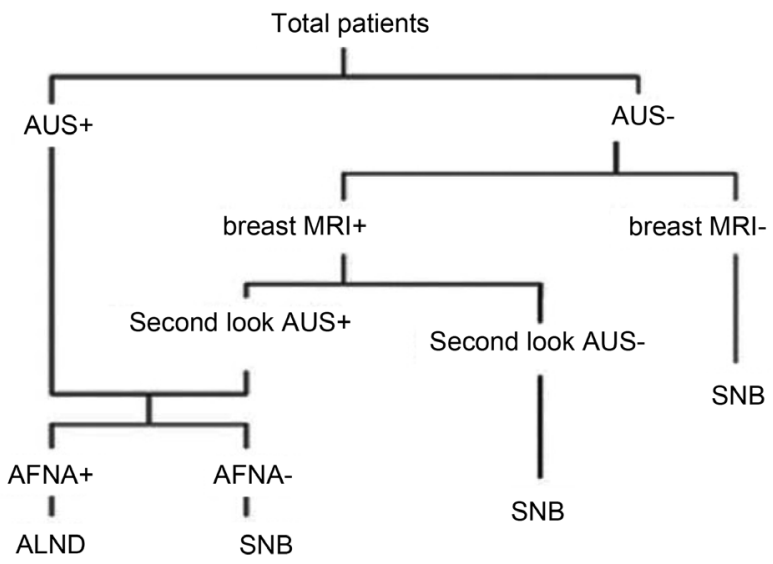

Figure 1. The flow diagram of the examinations and surgery process. AUS: axillary ultrasound, AFNA: axillary fine needle aspiration biopsy, SNB: sentinel lymph node biopsy, ALND: axillary node dissection. 
Systems, Japan) survey of the axillary lymph nodes in breast cancer patients. Ultrasound results were considered positive if a detected lymph node showed cortical thickening and loss of hilum.

\subsection{Breast MRI}

In our practice, we routinely perform breast MRI (1.5T scanner; Excite GE Healthcare, Milwaukee, WI) in breast cancer patients. Intravenous contrast was administered; agents used were gadobutrol, gadoterate meglumine, or gadoteridol. MRI results were considered positive (MRI diagnostic criteria) if significantly swollen axillary lymph nodes were detected, based on axillary lymph node size $>4 \mathrm{~mm}$, long-to-short axis ratio, cortical thickness-to-anteroposterior diameter ratio, and contrast enhancing patterns.

\subsection{Preoperative Evaluations}

Second-look AUS was performed if axillary LNM was not suspected on the initial AUS but was suspected on breast MRI. Patients with suspected axillary LNM on AUS or second-look AUS underwent active AFNA. First, AUS+ cases were divided into two groups, AFNA+ and AFNA-. Second, we evaluated cases with $L N M \geq 4$ in the two groups: patients who underwent ALND due to AFNA+ and due to $\mathrm{SN}+$. Third, to consider the usefulness of axillary evaluation by breast MRI, cases with findings on MRI but not on AUS were examined.

This retrospective study was approved by the research ethics committee (TGE00 606-060).

\subsection{Statistical Analysis}

The results were analyzed using descriptive statistical methods. The statistical significance of differences in proportions was assessed using the $\chi^{2}$ test. P values $<$ 0.05 were considered significant.

We examined the factors that have affected MRI result using multiple regression analysis.

\section{Results}

A total of 758 patients with breast cancer were enrolled into this study (stage Tis = 71 , stage $\mathrm{T} 1=526$, stage $\mathrm{T} 2=145$, stage $\mathrm{T} 3=16$ ). Mean age of the entire group was 55.7 years (range, 26 - 95). Table 1 shows the characteristics of all 758 patients. Table 2 shows the results of every operative procedure. Of 758, 193 (25\%) patients had axillary lymph node metastasis. The average number of positive axillary lymph nodes was 1.9 and 6.6 in the patients who underwent ALND due to $\mathrm{SN}+$ and AFNA+ findings, respectively. Among the patients with $\mathrm{LNM} \geq 4$, 664 with preoperative AUS- or AUS+/AFNA- findings underwent SN biopsy. A total of 81 patients (10.9\%) underwent ALND due to SN+ findings. Of these, six patients $(7.4 \%)$ had $L N M \geq 4$. However, among the patients who underwent ALND due to AUS+/AFNA+ findings, 46 (48.9\%) had LNM $\geq 4(\mathrm{P}<0.0001)$. 
Table 1. Patients characteristics.

\begin{tabular}{ccc}
\hline Age & Median age (y) & $55.7(26-95)$ \\
\hline & $\leq 40$ & $72(9 \%)$ \\
$41-50$ & $250(33 \%)$ \\
$51-60$ & $167(22 \%)$ \\
& $61-70$ & $152(20 \%)$ \\
& $71 \leq$ & $117(16 \%)$ \\
AUS & Negative & $626(83 \%)$ \\
MRI & Positive & $132(17 \%)$ \\
& Negative & $647(85 \%)$ \\
AFNA & Positive & $111(15 \%)$ \\
& Not done & $609(80 \%)$ \\
& AFNA+ & $94(63 \%)$ \\
Pathological tumor stage & AFNA- & $55(37 \%)$ \\
& Median size (mm) & 16.8 \\
& pTis & $71(9 \%)$ \\
& pT1 & $526(69 \%)$ \\
& pT2 & $145(19 \%)$ \\
& pT3 & $16(2 \%)$ \\
& Breast conserving surgery & $527(70 \%)$ \\
& Mastectomy & $231(30 \%)$ \\
\hline
\end{tabular}

AUS: axillary ultrasound, AFNA: axillary fine needle aspiration biopsy.

Table 2. The results of every operative procedure.

\begin{tabular}{|c|c|c|c|c|}
\hline & $\begin{array}{c}\text { BCS or } \\
\text { Mastectomy + } \\
\text { SNB (SN-) }\end{array}$ & $\begin{array}{c}\text { BCS or } \\
\text { Mastectomy + } \\
\text { SNB } \rightarrow \text { ALND }\end{array}$ & $\begin{array}{c}\text { BCS or } \\
\text { Mastectomy + } \\
\text { SNB (SN+) }\end{array}$ & $\begin{array}{c}\text { BCS or } \\
\text { Mastectomy + } \\
\text { ALND }\end{array}$ \\
\hline $\begin{array}{l}\text { Number of the } \\
\text { patients }\end{array}$ & 565 & 81 & 18 & 94 \\
\hline Median age & 56.1 & 53.6 & 56.2 & 59.5 \\
\hline $\begin{array}{c}\text { Median } \\
\text { invasion size }\end{array}$ & 14.5 & 17.2 & 26.8 & 31.0 \\
\hline $\begin{array}{l}\text { Median number } \\
\text { of axillary lymph } \\
\text { node metastasis }\end{array}$ & 0 & 1.9 & & 6.8 \\
\hline $\begin{array}{l}\text { Median number } \\
\text { of SN metastasis }\end{array}$ & 1.4 & 1.8 & 1.8 & \\
\hline $\begin{array}{c}\text { Median number } \\
\text { of non-SN } \\
\text { metastasis }\end{array}$ & & 0.8 & & \\
\hline $\begin{array}{l}\text { Median number } \\
\text { of non SN } \\
\text { removed }\end{array}$ & & 10.4 & & \\
\hline $\begin{array}{l}\text { Median number } \\
\text { of SN and non } \\
\text { SN removed }\end{array}$ & & 12.2 & & 16.8 \\
\hline
\end{tabular}

SNB: sentinel node biopsy, BCS: breast conserving surgery, ALND: axillary lymph node dissection, SN: sentinel lymph node. 
Then we considered the usefulness of MRI. First, we considered the accuracy of three types of examinations; ultrasonography excluding second look AUS without MRI, ultrasonography including a second look AUS combination of MRI, and MRI alone. Sensitivity and specificity of MRI were $44 \%$ and $96 \%$. There was no difference in these three evaluations (Table 3). Multivariate analyses showed axillary lymph nodes metastasis, and tumor size were significantly associated with MRI in patients (both of two; $\mathrm{P}<0.01$ ) (Table 4). Of the 607 AUS- cases, 38 were $\mathrm{MRI}+$, and 15 patients underwent AFNA due to second-look AUS. Of these 15 patients, 9 with AFNA+ and 6 with AFNA- results underwent SN biopsy. Two of the latter six patients had $\mathrm{SN}+$ results and one had $\mathrm{LNM} \geq 4$. However, of the nine AFNA+ cases, five had LNM $\geq 4$ (Figure 2). In addition, considering the

Table 3. Accuracy of examinations.

\begin{tabular}{ccccc}
\hline & & \multicolumn{3}{c}{ Pathology } \\
\cline { 3 - 4 } & & positive (193) & negative (565) & sum \\
\hline AUS & positive & $90(47 \%)$ & $35(7 \%)$ & 125 \\
(before MRI) & negative & $103(53 \%)$ & $530(93 \%)$ & 633 \\
MRI & positive & $85(44 \%)$ & $21(4 \%)$ & 106 \\
AUS & negative & $108(57 \%)$ & $544(96 \%)$ & 652 \\
$($ second look) & positive & $116(53 \%)$ & $39(7 \%)$ & 155 \\
\hline
\end{tabular}

Table 4. Multivariate analysis.

\begin{tabular}{ccc}
\hline & P-value & $95 \%$ CI \\
\hline Age & 0.2835 & $-0.0025-0.0007$ \\
Tumor size & $<0.001$ & $0.0055-0.0089$ \\
Axillary lymph node metastasis & $<0.001$ & $0.0306-0.0429$ \\
AUS & 0.1638 & $-0.0984-0.0167$ \\
\hline
\end{tabular}

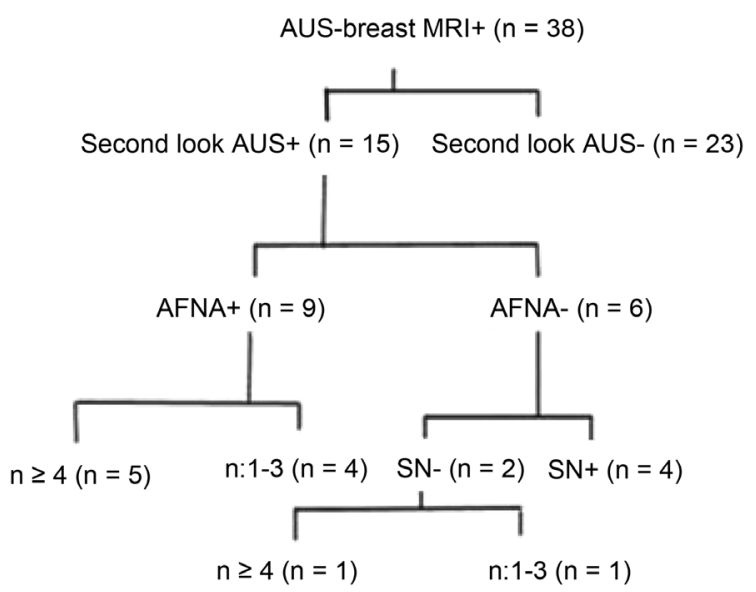

Figure 2. Axillary lymph node management in breast cancer patients. AUS: axillary ultrasound, AFNA: axillary fine needle aspiration biopsy, SNB: sentinel lymph node biopsy, SN: sentinel lymph node. 
use of breast MRI by the proportion of cases with $L N M \geq 4$, if MRI and second-look AUS had not been performed, we would have performed SN biopsy in 673 patients, 12 of whom (13.3\%) had LNM $\geq 4$. The proportion of cases with LNM $\geq 4$ was reduced from $13.3 \%$ to $7.4 \%$ among those in which a SN biopsy was performed combined with breast MRI.

\section{Discussion}

ALND has been a standard treatment method for patients with LNM; however, it is associated with complications, such as lymphedema, shoulder stiffness, breast edema, seroma formation, upper limb numbness, and brachial plexopathy [5] [6]. Regarding ALND omission, issues remain for patients with $\mathrm{SN}+$ findings. Although $\mathrm{LNM} \geq 4$ should be considered for RNI [7], propriety is unknown regarding ALND omission. The omission of ALND in surgical procedures for tumors with LNM has been considered, but remains controversial [8]. Various attempts have been made to predict axillary LNM to avoid ALND safely [9] [10]. Several predicting models have been developed [8] [11]-[18], and many studies have been done to select the best preoperative method for predicting axillary LNM [14] [15] [17] [18]. However, the best method to do so has not been established. Therefore, we evaluated the possibility of predicting LNM $\geq 4$ for safe omission of ALND in $\mathrm{SN}+$ cases. First, we reviewed each examination for axillary LNM. Accuracies of each examination were reported [9], with ultrasound found to be a suitable diagnostic tool for determining lymph node morphologic characteristics in the axilla, and histologic examination of lymph nodes, as well as sonographically guided AFNA [10]. AFNA is a simple, inexpensive, and minimally invasive technique that makes possible reduction in the numbers of SN biopsies performed [19] [20]. Previous studies have reported that the sensitivity of AFNA was low and the false-negative rate was high [7] [10] [19] [20]. In this study, all patients with AFNA+ findings had metastatic disease at ALND. On the other hand, many breast cancer patients currently undergo breast MRI as part of their initial preoperative workup. Though MRI is not recommended as a preoperative axillary evaluation method according to guidelines such as NCCN 2017 [4], integrating the information already gathered with regard to primary lesions and occult axillary lymph node risk will come at minimal additional cost. The capacity of breast MRI to predict additional axillary lymph node status is highly relevant for care of patients with $\mathrm{SN}+$ findings [15]. Although AUS has been reported to have a similar specificity but better sensitivity than MRI [14], AUS is a subjective examination and it has some problems. Preoperative surgical examination of axillary lymph nodes by AUS itself has good specificity. However, AUS alone is characterized by low sensitivity in defining the presence of metastasis [21] [22]. We decided to perform second-look AUS in patients with AUS- and axillary MRI+ results. The additional cytological assessment of axillary lymph nodes using AFNA improves sensitivity and reaches an absolute specificity of $100 \%$ for the diagnosis of metastasis [23] [24]. Incidentally, we reviewed the flow of surgery, and since January 2016, ALND has been omitted even in SN+ 
breast cancer cases to conserve surgery. We decided to perform axillary irradiation in these cases. The proportion of cases with $\mathrm{LNM} \geq 4$ was $13.3 \%$ if the SN biopsy was performed after active AFNA due to ultrasound findings. Further, when combined with MRI findings, the ratio decreased to $7.4 \%$. By case selection according to detailed preoperative evaluations and intentional AFNA, ALND might be omitted safely in $\mathrm{SN}+$ cases.

\section{Acknowledgements}

The authors appreciate Enago (https://www.enago.jp) for the English language review.

\section{References}

[1] Darby, S., Mc Gale, P., Correa, C., Taylor, C., Arriagada, R., Clarke, M., et al. (2011) Effect of Radiotherapy after Breast-Conserving Surgery on 10-Year Recurrence and 15-Year Breast Cancer Death: Meta-Analysis of Individual Patient Data for 10,801 Women in 17 Randomized Trials. Lancet, 378, 1707-1716. https://doi.org/10.1016/S0140-6736(11)61629-2

[2] Donker, M., van Tienhoven, G., Straver, M.E., Meijnen, P., van de Velde, C.J., Mansel, R.E., et al. (2014) Radiotherapy or Surgery of the Axilla after a Positive Sentinel Node in Breast Cancer (EORTC 10981-22023 AMAROS): A Randomized, Multicenter, Open-Label, Phase 3 Non-Inferiority Trial. The Lancet Oncology, 15, 1303-1310. https://doi.org/10.1016/S1470-2045(14)70460-7

[3] Whelan, T.J., Olivotto, I.A., Parulekar, W.R., Ackerman, I., Chua, B.H., Nabid, A., et al. (2015) Regional Nodal Irradiation in Early-Stage Breast Cancer. The New England Journal of Medicine, 373, 307-316. https://doi.org/10.1056/NEJMoa1415340

[4] National Comprehensive Cancer Network (NCCN) (2017) NCCN Clinical Practice Guidelines in Oncology (NCCN Guidelines). Breast Cancer Version 2017. https://www.nccn.org/index.asp

[5] Tan, L.G., Tan, Y.Y., Heng, D. and Chan, M.Y. (2005) Predictors of Axillary Lymph Node Metastases in Women with Early Breast Cancer in Singapore. Singapore Medical Journal, 46, 693-697.

[6] Roses, D.F., Brooks, A.D., Harris, M.N., Shapiro, R.L. and Mitnick, J. (1999) Complications of Level I and II Axillary Dissection in the Treatment of Carcinoma of the Breast. Annals of Surgery, 230, 194-201.

https://doi.org/10.1097/00000658-199908000-00009

[7] Castellano, I., Deambrogio, C., Muscarà, F., Chiusa, L., Mariscotti, G., Bussone, R., et al. (2014) Efficiency of a Preoperative Axillary Ultrasound and Fine-Needle Aspiration Cytology to Detect Patients with Extensive Axillary Lymph Node Involvement. PLoS One, 9, 1-6. https://doi.org/10.1371/journal.pone.0106640

[8] Martin, C., Cutuli, B. and Velten, M. (2002) Predictive Model of Axillary Lymph Node Involvement in Women with Small Invasive Breast Carcinoma Axillary Metastases in Breast Carcinoma. Cancer, 94, 314-322.

https://doi.org/10.1002/cncr.10229

[9] Joseph, K.A., El-Tamer, M., Komenaka, I., Troxel, A., Ditkoff, B.A. and Schnabel, F. (2004) Predictors of Nonsentinel Node Metastasis in Patients with Breast Cancer after Sentinel Node Metastasis. Archives of Surgery, 139, 648-651.

https://doi.org/10.1001/archsurg.139.6.648 
[10] Ahn, H., Kim, S., Jang, M., La Yun, B., Kim, S.W., Kang, E., et al. (2013) Comparison of Sonography with Sonographically Guided Fine-Needle Aspiration Biopsy and Core-Needle Biopsy for Initial Axillary Staging of Breast Cancer. Journal of UItrasound in Medicine, 32, 2177-2184. https://doi.org/10.7863/ultra.32.12.2177

[11] Takada, M., Sugimoto, M., Naito, Y., Moon, H.G., Han, W., Noh, D.Y., et al. (2012) Prediction of Axillary Lymph Node Metastasis in Primary Breast Cancer Patients using a Decision Tree-Based Model. BMC Medical Informatics and Decision Making, 13, 54. https://doi.org/10.1186/1472-6947-12-54

[12] Chue, K.M., Yong, W.S., Thike, A.A., Ahmed, S.S., Li, H.H., Wong, C.Y., et al. (2014) Predicting the Likelihood of Additional Lymph Node Metastasis in Sentinel Lymph Node Positive Breast Cancer: Validation of the Memorial Sloan-Kettering Cancer Centre (MSKCC) Nomogram. Journal of Clinical Pathology, 67, 112-119. https://doi.org/10.1136/jclinpath-2013-201524

[13] Coutant, C., Olivier, C., Lambaudie, E., Fondrinier, E., Marchal, F., Guillemin, F., et al. (2009) Comparison of Models to Predict Nonsentinel Lymph Node Status in Breast Cancer Patients with Metastatic Sentinel Lymph Nodes: A Prospective Multicenter Study. Journal of Clinical Oncology, 27, 2800-2808. https://doi.org/10.1200/JCO.2008.19.7418

[14] Valente, S.A., Levine, G.M., Silverstein, M.J., Rayhanabad, J.A., Weng-Grumley, J.G., Ji, L., et al. (2012) Accuracy of Predicting Axillary Lymph Node Positivity by Physical Examination, Mammography, Ultrasound, and Magnetic Resonance Imaging. Annals of Surgical Oncology, 19, 1825-1830. https://doi.org/10.1245/s10434-011-2200-7

[15] Loiselle, C., Eby, P.R., Kim, J.N., Calhoun, K.E., Allison, K.H., Gadi, V.K., et al. (2014) Preoperative MRI Improves Prediction of Extensive Occult Axillary Lymph Node Metastases in Breast Cancer Patients with a Positive Sentinel Lymph Node Biopsy. Academic Radiology, 21, 92-98. https://doi.org/10.1016/j.acra.2013.10.001

[16] Kijima, Y., Yoshinaka, H., Hirata, M., Mizoguchi, T., Ishigami, S., Nakajo, A., et al. (2010) Number of Axillary Lymph Node Metastases Determined by Preoperative Ultrasound Is Related to Prognosis in Patients with Breast Cancer. Cancers, 2, 20-31. https://doi.org/10.3390/cancers2010020

[17] Abe, H., Schacht, D., Sennett, C.A., Newstead, G.M. and Schmidt, R.A. (2013) Utility of Preoperative Ultrasound for Predicting pN2 or Higher Stage Axillary Lymph Node Involvement in Patients with Newly Diagnosed Breast Cancer. American Journal of Roentgenology, 200, 696-702. https://doi.org/10.2214/AJR.12.9036

[18] Sato, K., Tamaki, K., Tsuda, H., Kosuda, S., Kusano, S., Hiraide, H., et al. (2004) Utility of Axillary Ultrasound Examination to Select Breast Cancer Patients Suited for Optimal Sentinel Node Biopsy. The American Journal of Surgery, 187, 679-683. https://doi.org/10.1016/j.amjsurg.2003.10.012

[19] Altomare, V., Guerriero, G., Carino, R., Battista, C., Primavera, A., Altomare, A., et al. (2007) Axillary Lymph Node Echo-Guided Fine-Needle Aspiration Cytology Enables Breast Cancer Patients to Avoid a Sentinel Lymph Node Biopsy. Preliminary Experience and a Review of the Literature. Surgery Today, 37, 735-739. https://doi.org/10.1007/s00595-006-3366-7

[20] Diaz-Ruiz, M.J., Arnau, A., Montesinos, J., et al. (2016) Diagnostic Accuracy and Impact on Management of Ultrasound-Guided Fine-Needle Aspiration to Detect Axillary Metastasis in Breast Cancer Patients: A Prospective Study. Breast Care (Basel), 11, 34-39. https://doi.org/10.1159/000442481

[21] Lee, B., Lim, A.K., Krell, J., Satchithananda, K., Coombes, R.C., Lewis, J.S., et al. (2013) The Efficacy of Axillary Ultrasound in the Detection of Nodal Metastasis in 
Breast Cancer. American Journal of Roentgenology, 200, 314-320. https://doi.org/10.2214/AJR.12.9032

[22] Alvarez, S., Añorbe, E., Alcorta, P., López, F., Alonso, I. and Cortés, J. (2006) Role of Sonography in the Diagnosis of Axillary Lymph Node Metastases in Breast Cancer: A Systematic Review. American Journal of Roentgenology, 186, 1342-1348. https://doi.org/10.2214/AJR.05.0936

[23] Sapino, A., Cassoni, P., Zanon, E., Fraire, F., Croce, S., Coluccia, C., et al. (2003) Ultrasonographically-Guided Fine-Needle Aspiration of Axillary Lymph Nodes: Role in Breast Cancer Management. British Journal of Cancer, 88, 702-706. https://doi.org/10.1038/sj.bjc.6600744

[24] Krishnamurthy, S., Sneige, N., Bedi, D.G., Edieken, B.S., Fornage, B.D., Kuerer, H.M., et al. (2002) Role of Ultrasound-Guided Fine-Needle Aspiration of Indeterminate and Suspicious Axillary Lymph Nodes in the Initial Staging of Breast Carcinoma. Cancer, 95, 982-988. https://doi.org/10.1002/cncr.10786 